\title{
Applications of the COST Plasma Jet: More than a Reference Standard
}

\author{
Yury Gorbanev $1, *\left(\mathbb{D}\right.$, Judith Golda ${ }^{2,3}$, Volker Schulz-von der Gathen ${ }^{3}$ and \\ Annemie Bogaerts ${ }^{1}$ (D) \\ 1 Research group PLASMANT, Department of Chemistry, University of Antwerp, Universiteitsplein 1, \\ 2610 Wilrijk, Belgium \\ 2 Institute for Experimental and Applied Physics, Kiel University, Leibnizstraße 19, 24118 Kiel, Germany \\ 3 Chair for Experimental Physics II: Reactive plasmas, Ruhr-University Bochum, Universitätsstraße 150, \\ 44801 Bochum, Germany \\ * Correspondence: yury.gorbanev@uantwerpen.be; Tel.: +32-(0)-326-52-343
}

Received: 26 June 2019; Accepted: 10 July 2019; Published: 12 July 2019

check for updates

\begin{abstract}
The rapid advances in the field of cold plasma research led to the development of many plasma jets for various purposes. The COST plasma jet was created to set a comparison standard between different groups in Europe and the world. Its physical and chemical properties are well studied, and diagnostics procedures are developed and benchmarked using this jet. In recent years, it has been used for various research purposes. Here, we present a brief overview of the reported applications of the COST plasma jet. Additionally, we discuss the chemistry of the plasma-liquid systems with this plasma jet, and the properties that make it an indispensable system for plasma research.
\end{abstract}

Keywords: COST microplasma jet; reference plasma jet; $\mu$-APPJ; plasma chemistry; plasma applications; biomedical plasma; plasma-liquid interactions; plasma RONS; plasma-polymer interactions; nanomaterials

\section{Introduction}

Among the various types of plasma, non-thermal (or 'cold') atmospheric pressure plasma (CAP) is perhaps the most burgeoning field [1,2]. CAPs find their applications in biomedical, chemical, environmental/energy and industrial research [1,3-5]. As a result of the extensive range of applications, a plethora of plasma devices have been developed and reported in literature.

In turn, among the various types of plasma setups, atmospheric pressure plasma jets (APPJs) are some of the most widely used devices due to their unique properties [6,7]. Operated at ambient temperature and pressure, they enable direct treatment of temperature-sensitive substrates, including biological targets (cells, tissues, agricultural materials, etc.). APPJs in many cases have a minimised electrical impact during plasma treatment, while at the same time facilitating targeted delivery of the biologically active reactive oxygen and nitrogen species (RONS) due to the flow of gas. These RONS comprise long-lived ones (molecules and ions) and short-lived ones (radicals and atoms), and define the potential of CAPs in (among others) biomedical applications [8,9].

APPJs are operated with a flow of feed gas between the electrodes. This flow of gas is responsible for the term 'jet'. The feed gas is usually an inert gas (e.g., Ar or He, pure or with added molecular admixtures $[10,11])$, although in certain cases nitrogen or air is used [12]. The RONS are created either inside the jet, or when the effluent of the jet interacts with the ambient atmosphere [13]. Furthermore, APPJs can be discriminated based on the parameters of the discharge (pulsed or continuous sinusoidal), frequency (e.g., kHz, MHz), and configuration of the electrodes, etc. The electrode configuration allows 
distinguishing between the two types of APPJs: Parallel field and cross field APPJs. In the former, the applied electric field is parallel to the gas flow, and in the latter, it is perpendicular $[3,7,14]$.

Thus, there are numerous differences in properties and effects of CAP applications even within the various APPJs. Despite being necessary for the field to progress, this variety of APPJs creates difficulties in comparison between results, and in deconvolution of plasma effects.

To address these issues, within the European Cooperation for Science and Technology (COST) action MP1101 'Biomedical Applications of Atmospheric Pressure Plasmas' [15] the COST reference Microplasma Jet was developed from its predecessor, the $\mu$-APPJ.

In short, the COST jet comprises two stainless steel electrodes of $30 \mathrm{~mm}$ length and $1 \mathrm{~mm}$ width. Extensions allow the connection with the power supply, as shown in Figure 1. The distance between the electrodes is $1 \mathrm{~mm}$. The electrodes are sealed between quartz panes, thus forming a discharge volume of $30 \mathrm{~mm}^{3}$. Feed gas, typically a mixture of helium and a molecular admixture in the percent range, is introduced into this electrode stack through the gas connector made from ceramics. Gas flows in the range of 0.25 to several standard litres per $\min (\mathrm{slm})$ yield stable operation. Molecular admixtures can range up to a few vol\% depending on the type of admixture. For the standard gas flow of $1 \mathrm{slm}$, an effluent velocity of about $15 \mathrm{~m} / \mathrm{s}$ is obtained. The length of the electrodes ensures that a plasma chemical equilibrium is established in the discharge region before the feed gas leaves the plasma jet [16,17]. The evolution of the equilibrium throughout the complete plasma channel can be investigated and surveyed for the COST jet due to the direct optical access through the quartz panes.
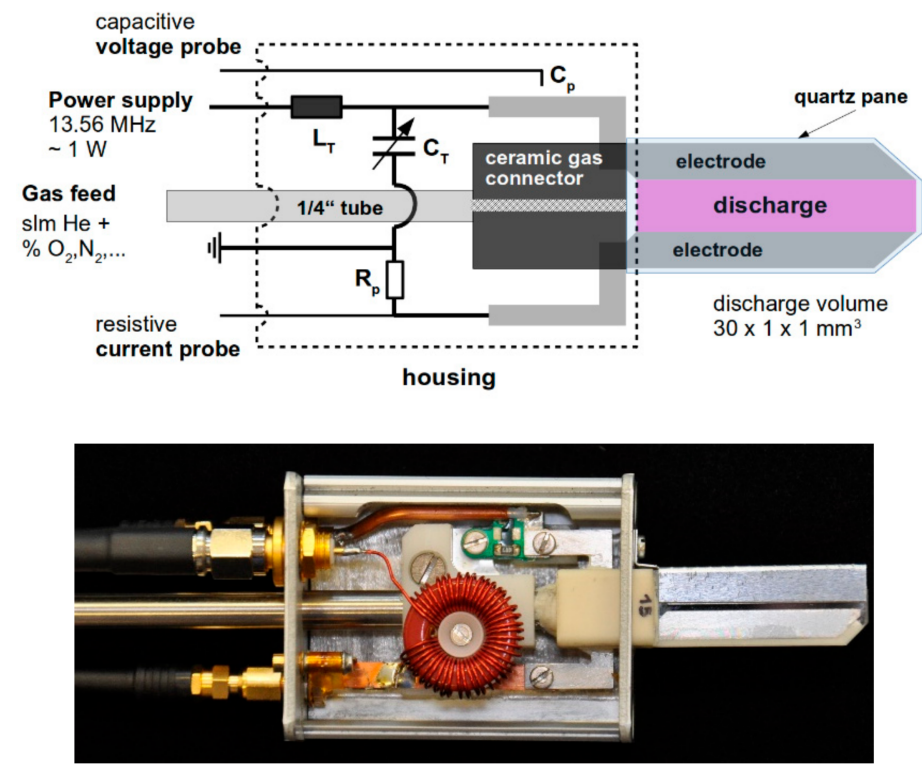

Figure 1. The schematics (top) and a photograph (bottom) of the European Cooperation for Science and Technology (COST) plasma jet.

We note that these parameters and design features are based on results from the thoroughly investigated predecessor-the $\mu$-APPJ. The configuration of that is very similar, allowing to assume comparable results. The COST jet is operated with a capacitively coupled RF frequency of $13.56 \mathrm{MHz}$ at ca. $1 \mathrm{~W}$ and a voltage of ca. $200-250 \mathrm{~V}_{\mathrm{RMS}}$.

To ensure and control proper operation, two probes are integrated into the COST-jet design directly connected to the electrodes. For current measurements, a precision resistor $\left(R_{P}\right)$ is used. Voltage measurements are realised by a pin probe $\left(C_{P}\right)$ at the powered electrode. The combined measurement of the current, voltage and phase allows the measurement of the power input into the electrode stack. The latter together with the inductance $\mathrm{L}_{\mathrm{T}}$ and the tunable capacitance $\mathrm{C}_{\mathrm{T}}$ form a part of a resonance circuit that allows the use of a low power, low voltage power supply providing sinusoidal waveforms. Other supplies can be fitted that allow for other waveforms and frequencies or pulsed operation of the 
jet, although they are not included in the original COST jet definition. All components are installed inside a grounded housing that shields the whole assembly against external stray capacitances.

Further details of the physical properties, as well as the electrical and gas phase plasma diagnostics of the COST jet, and procedure protocols for reproducible operation are comprehensively described in an earlier work [18]. A set of modified COST jet configurations was developed and characterized that allows the separation of the particle and photons to study their isolated or combined effects [19]. Moreover, accurate computational models have been developed to predict the chemical kinetics in the gas phase [20-22].

Overall, the possibility to control, tune and reproduce the gas phase plasma properties of the COST jet and modified jets make them highly useful plasma setups.

In this review, we summarise the main advances in the applications of the COST plasma jet. Specifically, we focus on the insights into plasma chemistry gained by using the COST jet. Here we report the use of the COST jet together with its predecessor $\mu$-APPJ, which have virtually the same properties, as mentioned above. Henceforth, we refer to both as 'the COST jet' to maintain clarity.

\section{Applications of the COST Plasma Jet}

\subsection{Interaction with Organic Polymers}

The applicability of an APPJ to specific purposes is largely defined by the induced chemistry. The aforementioned tunability of the COST jet (and COST jet-based modified plasma setups) allows controlled generation of RONS in the gas phase $[19,23]$. Specifically, when operated with a feed gas of He with $\mathrm{O}_{2}$ admixtures, the main 'output' reactive oxygen species (ROS) are atomic oxygen $\mathrm{O}$, singlet oxygen ${ }^{1} \mathrm{O}_{2}$, and ozone $\mathrm{O}_{3}[24,25]$. These ROS are of high importance in the field of material research. For example, highly chemically reactive atomic and radical species generated by plasma $[8,13]$ can interact with polymer surfaces in various ways.

\subsubsection{Photoresist Removal}

In the micro-nano-electronics industry, the production of lithographic patterns proceeds through several steps, required to generate advanced nanoscale structures. The removal of photoresistant polymers (or plasma etching) between the processing steps is used. Commonly, this is done by using low-pressure plasmas, the operation of which is costly and can damage the substrate surface [26,27].

An alternative to this method was suggested by West et al. [27]. Since in the COST jet the applied field is perpendicular to the gas flow, the charged species, including high energy electrons, are largely confined within the jet. This eliminates the danger of sheath formation when the effluent of the jet interacts with targets.

The COST jet was operated at 13.56 and $40.68 \mathrm{MHz}$, with a feed gas of $\mathrm{He}$ with $\mathrm{O}_{2}$ admixtures. It was used to remove novolak polymers from a silicon wafer. It was found that under the investigated conditions, an admixture of $0.5 \% \mathrm{O}_{2}$ resulted in the highest rate of photoresist etching. The authors reported that $0.5 \% \mathrm{O}_{2}$ in He yielded the highest amount of atomic $\mathrm{O}$, which also corresponded to the highest rate of etching. $\mathrm{O}$ was suggested to be the main species responsible for the polymer removal. The highest etching rate achieved by West et al. was $10 \mu \mathrm{m} / \mathrm{min}$, with a total gas flow rate of $7 \mathrm{~L} / \mathrm{min}$. This etching rate is comparable to those required by the semiconductor industry, while being substantially more benign for the underlying surface.

Very recently, Hefny et al. showed that when the COST jet $\mathrm{He}+\mathrm{O}_{2}$ plasma interacts with surfaces, such as e.g., amorphous carbon films, the probability of the surface loss of $\mathrm{O}$ atoms is low (below $1 \%$ ). This results in high densities of $\mathrm{O}$ atoms not only in the area of the immediate contact of the plasma effluent with the surface, but also radially on the surrounding thin film, making the COST jet a useful tool in studying the surface processes occurring during CAP etching [28]. 


\subsubsection{Studying the Main Agents Used in Polymer Surface Modification}

Polymers are widely used in the packaging industry, for textile, and in medical applications, often in combination with plasma technology [29]. The low wettability of polymers can be a problem that needs resolving. The increased hydrophilicity of the polymer surface is achieved by using industrial plasmas, but the chemistry which yields the desired properties of polymers is not well known [30].

Shaw et al. investigated the chemical species and mechanisms leading to the induction of wettability in polypropylene films [31]. Once again, here the COST jet was used as a system without an active effluent: the 'output' of the jet was comprised of highly chemically reactive atoms and radicals, but contained no high energy species such as plasma electrons.

The authors assessed the wettability from the contact angle between water droplets and the polymer surface as a function of various plasma parameters. Similar to the etching study, the laser induced fluorescence analysis showed that most $\mathrm{O}$ atoms were produced in the studied system when He was used with ca. $0.5 \% \mathrm{O}_{2}$. This $\mathrm{O}_{2}$ admixture also corresponded to the highest wettability achieved. The surface analysis revealed the formation of $\mathrm{C}=\mathrm{O}$ moieties corresponding to both ketones and carboxylic acids.

This demonstrates that the COST jet-induced chemistry (e.g., O-based) can be used both for complete etching of target polymers, and for mild oxidative transformation of the surface groups leading to increased wettability of polymers, depending on the specific parameters of plasma operation.

\subsection{Preparation of Silicon-Based Films}

Silicon dioxide is a common material for the production of thin films, which find their use in anti-corrosive or scratch-resistant coatings [32]. One of the most attractive ways to deposit these films is with CAPs, which allow reducing production costs by avoiding vacuum plasma technologies currently used [33].

Reuter et al. used the COST jet and its modified versions to study the plasma-driven deposition of silicon thin films with a specific chemical composition [32]. The plasma jet was operated with a feed gas of He with hexamethyldisiloxane (HMDSO). The authors investigated the effect of ROS present in the deposition process. $\mathrm{O}_{2}$ either was added in a closed reactor with another jet $\left(\mathrm{He}+\mathrm{O}_{2}\right.$, generating ROS), or diffused into the effluent from the ambient air. By studying the resulting film properties with FTIR, it was found that the carbon content of the deposited films depended largely on the presence of $\mathrm{O}_{2}$ : A He+HDMSO plasma jet yielded high C content films, while $\mathrm{He}+\mathrm{HDMSO}$ with $\mathrm{He}+\mathrm{O}_{2}$ or with $\mathrm{O}_{2}$ from the ambient air gave predominantly a Si-O-Si bond formation. The authors suggested that: (i) The He+HDMSO plasma jet produced Si-C rich thin films; (ii) they further interacted with atomic O or other ROS, leading to the loss of carbon. This was further confirmed by the ellipsometry and XPS analyses of the thin film produced by adding both HDMSO and $\mathrm{O}_{2}$ into the He feed gas [34].

Further, Rügner et al. proposed reaction pathways leading to thin films with high Si-O and low $\mathrm{Si}-\mathrm{C}$ content [35]. The addition of $\mathrm{O}_{2}$ yielded ROS which lead to additional Si-O bonds in the gas phase plasma. This generates O-centred radical structures with a high affinity to surface deposition. Furthermore, the remaining methyl substituents on $\mathrm{Si}$ are removed via oxidation to $\mathrm{CO}_{2}$, in turn leading to crosslinking and creating Si-O-Si structures (Scheme 1). 


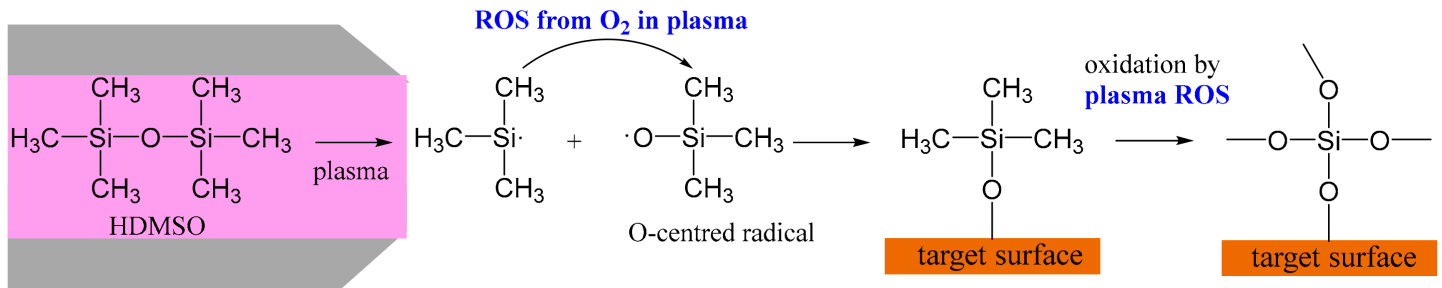

Scheme 1. The use of the COST jet to study the reactions leading to $\mathrm{SiO}_{2}$-based thin films deposited by cold atmospheric pressure plasma (CAP).

Thus, the plasma generated with the COST jet proved useful in studying many fundamental properties of $\mathrm{SiO}_{2}$ film deposition and the effect of other plasma RONS.

\subsection{COST Jet for Inorganic and Organic Chemistry}

One of the unique properties of the COST jet is its ability to produce ROS in the gas phase with high selectivity, as we discussed above. Additionally, and perhaps more importantly, it was also shown by studying the oxidative transformations of phenolic compounds in water that the COST jet is a very effective instrument to induce $\mathrm{O}$ atoms in liquid solutions [36,37]. In general, CAPs are unique systems for the delivery of short-lived species (atoms and radicals) [38], very sought-after in chemical applications, as we demonstrate below.

\subsubsection{Studying the Reaction between Atomic $\mathrm{O}$ and $\mathrm{Cl}^{-}$in the Liquid Phase}

Due to the difficulties in selective induction of atomic oxygen into liquids, its reactions in aqueous solutions are largely unknown. One of such reactions is the oxidation of $\mathrm{Cl}^{-}$, which was recently proposed by Kondeti et al. [39].

This reaction was studied using a COST jet operated with the $\mathrm{He}+\mathrm{O}_{2}$ feed gas. The produced plasma interacted with solutions containing $\mathrm{Cl}^{-}$anions. We studied the production of various RONS: (i) Experimentally in aqueous solutions by measuring their concentrations with UV-Vis and EPR analyses, and (ii) computationally in the gas phase using OD chemical kinetics modelling (enabled by the well-studied kinetic models of the gas phase plasma of the COST jet). The results showed nearly identical trends of atomic $\mathrm{O}$ densities in the gas phase and the $\mathrm{ClO}^{-}$formed in the liquid phase. Importantly, the concentrations of other RONS which could potentially oxidise $\mathrm{Cl}^{-}\left(\mathrm{H}_{2} \mathrm{O}_{2}, \mathrm{O}_{3},{ }^{1} \mathrm{O}_{2}\right.$, $\bullet \mathrm{OH}, \bullet \mathrm{OOH}$ ) did not follow similar trends. This allowed us to suggest that $\mathrm{ClO}^{-}$is formed via the direct oxidation of $\mathrm{Cl}^{-}$by $\mathrm{O}$ atoms [25]. This was also confirmed by Jirásek et al., who used the COST jet with $\mathrm{He}+\mathrm{O}_{2}$ to treat chloride-rich solutions at high $\mathrm{pH}$. The authors also observed the products of further oxidation: $\mathrm{ClO}_{2}{ }^{-}$and $\mathrm{ClO}_{3}{ }^{-}$[40] (Scheme 2). The reaction rate coefficient of $\mathrm{O}$ with $\mathrm{Cl}^{-}$was estimated to be relatively 2-3 orders of magnitude lower than of $\mathrm{O}$ with 2,2,6,6-tetramethylpiperidine [25] and of $\mathrm{O}$ with phenol [40]. More accurate evaluation requires additional kinetic investigations.

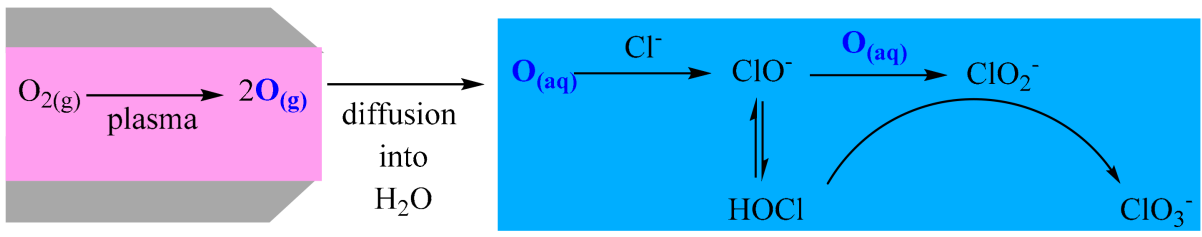

Scheme 2. Use of the COST jet as an efficient source of oxygen $(\mathrm{O})$ atoms to study reaction pathways in the oxidation of $\mathrm{Cl}^{-}$in aqueous media.

These were the first studies of this previously undescribed chemical reaction, very important for fundamental chemistry research. They also have large implications on the in-liquid chemistry of CAP-treated solutions, especially in biomedical research. 


\subsubsection{Epoxidation of Trans-Stilbene with Atomic O}

Epoxidation of olefins is an important chemical reaction yielding organic epoxides, key building blocks in organic synthesis. Epoxidations are typically performed with peroxy acids or other sacrificial oxygen donors, and/or catalysed by complex catalysts which are often not easily recyclable [41]. This creates separation, cost-effectiveness and environment-related issues by producing chemical waste.

In the context of benign, nearly zero-waste chemical agents, CAP-generated RONS present an attractive alternative to conventional chemical routes for organic synthesis [42].

Iza et al. studied the possibilities of epoxidation of trans-stilbene by various reactive species [43]. The authors utilised the COST jet operated with $\mathrm{He}+\mathrm{O}_{2}$ and $\mathrm{He}+\mathrm{CO}_{2}$. In both cases, the ROS that yielded the desired epoxide was the atomic $\mathrm{O}$. This was shown by using an $\mathrm{O}_{3}$ generator and ${ }^{1} \mathrm{O}_{2}$-producing photochemical system, neither of which produced large amounts of the epoxidation product. In the case of the $\mathrm{He}+\mathrm{CO}_{2} \mathrm{APPJ}$, the by-product of the reaction was $\mathrm{CO}$. Direct plasma-driven $\mathrm{CO}_{2}$ conversion to $\mathrm{CO}$, although attracting much attention, is hindered by the reverse reaction of $\mathrm{CO}$ with $\mathrm{O}$ atoms [5]. Trans-stilbene in this case acted as a quencher for $\mathrm{O}$, minimising this effect (Scheme 3). Exposing a solution of trans-stilbene in acetonitrile to these two effluents of the COST jet, the highest epoxide yield was ca. $60 \%$, proving the feasibility of such waste- and catalyst-free epoxidation process.

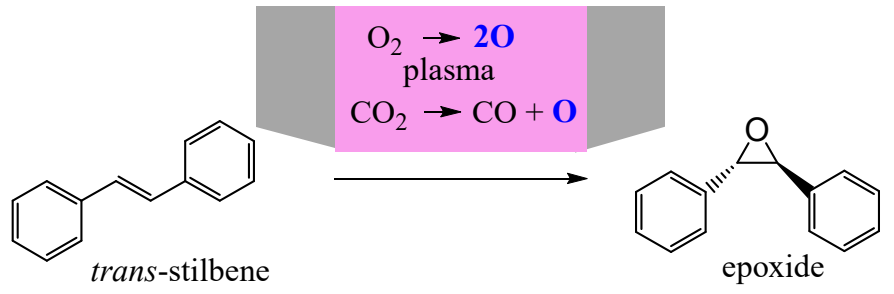

Scheme 3. Use of the COST jet as a waste-free benign chemical system for the epoxidation of trans-stilbene, providing high yield and conversion values.

\subsection{Biomedical Research}

Cold plasma medicine is one of the most extensive fields of CAP research. It comprises many applications, from cosmetic dentistry and biomedical materials production $[1,9,29]$ to bacterial deactivation [39,44] and anti-cancer therapy [38,45].

Despite the significant progress in the field of biomedical CAP, the underlying mechanisms are far from understood. It is generally assumed that the majority of the observed biomedical effects is due to the extremely high chemical reactivity of RONS. However, the main RONS (or even their nature: long- or short-lived) responsible for the medicinal effects of CAP are mostly not known $[38,46]$.

The deconvolution of the combined RONS effects becomes possible by using a CAP system with tunable production of reactive species, such as the COST jet. However, in biomedical milieu, RONS from the gas phase interact with liquid water present in every biological system. Therefore, studying the mechanisms of this interaction is required to evaluate the said tunability [10].

In a combined experimental and computational study, the sources of RONS induced by the COST jet in an exposed liquid were identified. This required differentiating between the water from the exposed liquid, water in the feed gas, and water in the effluent of the jet. It was done by isolating all components of the jet from the ambient air and using isotopically labelled water molecules [47]. As a result, it was found that even in the interaction with liquids, RONS produced by the COST jet are formed almost exclusively inside the plasma jet, from the components of the feed gas. In the effluent, these non-charged species further interact with each other and the components of air. Since the high energy species are absent in the COST jet effluent, virtually no new reactive species are formed from the air and $\mathrm{H}_{2} \mathrm{O}$ vapour [48].

Therefore, even the small admixtures to the feed gas of the COST jet play a more important role than the composition of the ambient air (e.g., humidity level). This once again emphasises the 'standard' nature of the COST jet, which enables its usage in different environments comparably and controllably. 


\subsubsection{Studying Bactericidal Effects of CAPs}

Treatments of chronic wounds with CAPs result in expedited healing, partly due to the efficient bacterial deactivation $[9,44]$. CAPs consist of different groups of physical and chemical components: (UV) photons, electric fields, charged and neutral particles [1,13]. Although numerous reports are available in literature on bacterial deactivation by exposure to cold plasma, the effect of these groups is not clearly understood.

Lackmann et al. used the COST jet to decouple the effects of various plasma-generated components on bacteria. The authors used modifications of the COST jet, which enabled the flux of (i) only photons; (ii) only RONS; (iii) combined fluxes of photons and RONS, while the gas flow onto the target remained the same under all experimental conditions. The most pronounced anti-bacterial effects were observed when the effluent with the combined flux was used: DNA damage, chemical modifications to protein and cell envelope were all the highest in this case. This indicated that the anti-bacterial effects of plasma can extend beyond the generation and delivery of RONS, and include the synergistic effects of UV photons and RONS combined [49].

Furthermore, the generalised effects of plasma RONS on proteins were studied using cysteine as a model molecule. Using a He-only fed COST jet, almost no changes in the cysteine structure were detected, whereas adding $\mathrm{O}_{2}$ admixtures to He revealed multiple oxidation sites [50], expectedly due to the generation of highly oxidising $\mathrm{O}$ atoms. Here, the COST jet was used as a plasma device without an active effluent, as opposed to plasmas with high densities of high-energy particles in the effluent [10].

\subsubsection{Identifying Optimal Parameters for Anti-CANCER treatments}

CAP cancer therapy is one of the most promising anti-cancer modalities [9,45]. When combined with other treatments and surgical methods, the chance of the recurrence of tumour formation can be substantially reduced.

The number of studies on the CAP treatment of cancer cells has dramatically increased in recent years. Yet, similar to the anti-bacterial properties of cold plasma, the exact plasma components and the mechanisms responsible for the plasma effects are not explicitly known.

Vermeylen et al. used the COST jet operated with the $\mathrm{He}+\mathrm{O}_{2}$ feed gas to study the effects of various parameters on the treatment of different melanoma and glioblastoma cell lines [51]. While the viability of all cell types was reduced as a result of plasma treatment, some appeared to be more susceptible to it than the others. This study tackled one of the most highlighted problems that plasma medicine research is trying to solve: Determining the potential selectivity of CAP treatment on cancer cells compared to benign cells [52]. The COST jet was used under conditions producing high densities of $\mathrm{O}$ atoms.

Bekeschus et al. showed that the $\mathrm{O}$ atoms were one of the main RONS leading to the apoptotic death of leukemia cells [53]. The authors used the COST jet operated with the He with the $\mathrm{H}_{2} \mathrm{O}$ and/or $\mathrm{O}_{2}$ admixtures. The authors identified liquid phase reactions leading to $\mathrm{ClO}^{-}$formation (see above) and other RONS leading to cell death. At the same time, $\mathrm{H}_{2} \mathrm{O}_{2}$, often considered to be the main biomedical effecter among the plasma-induced RONS [53,54], did not play an important role in the plasma-elicited effects.

The COST jet was also used in the comparative use of plasma-treated media as opposed to the direct plasma treatment [51]. This addresses one of the main reasons for the scepticism towards plasma medicine. Direct plasma treatment provides targeted delivery of highly short-lived RONS during treatment, while plasma-treated media generates persistent and semi-persistent molecular and ionic compounds, including e.g., $\mathrm{H}_{2} \mathrm{O}_{2}$, nitrous and peroxynitrous acid [13,55]. These compounds are commercially available, and their use technically does not require the employment of cold plasma.

A study was conducted determining the main RONS effecters on 3D tumour models (spheroids), which represent real in vivo tumours in a more realistic manner [56]. The spheroids consisted of glioblastoma cancer cells, and were subjected to treatments by the COST jet fed with the He feed gas with $\mathrm{H}_{2} \mathrm{O}$ vapour admixtures. The main RONS induced by this APPJ in liquid were the $\mathrm{H}_{2} \mathrm{O}_{2}$, 
$\mathrm{NO}_{2}{ }^{-}$, and $\bullet \mathrm{OH}$ radicals. The effects of the direct plasma treatment and the CAP-treated media were compared. Despite the substantial short-term effects from the treated media (which was practically identical to the solutions prepared from the commercial chemicals such as $\mathrm{H}_{2} \mathrm{O}_{2}$ ), the long-term effects were only observed in the case of direct CAP treatment (Figure 2). Therefore, the short-lived radical species were proposed to be the key RONS for efficient tumour treatment. This indeed implies the need for plasma usage in cancer therapy, where plasma acts as a unique physicochemical system for the generation and delivery of short-lived RONS [38,56].

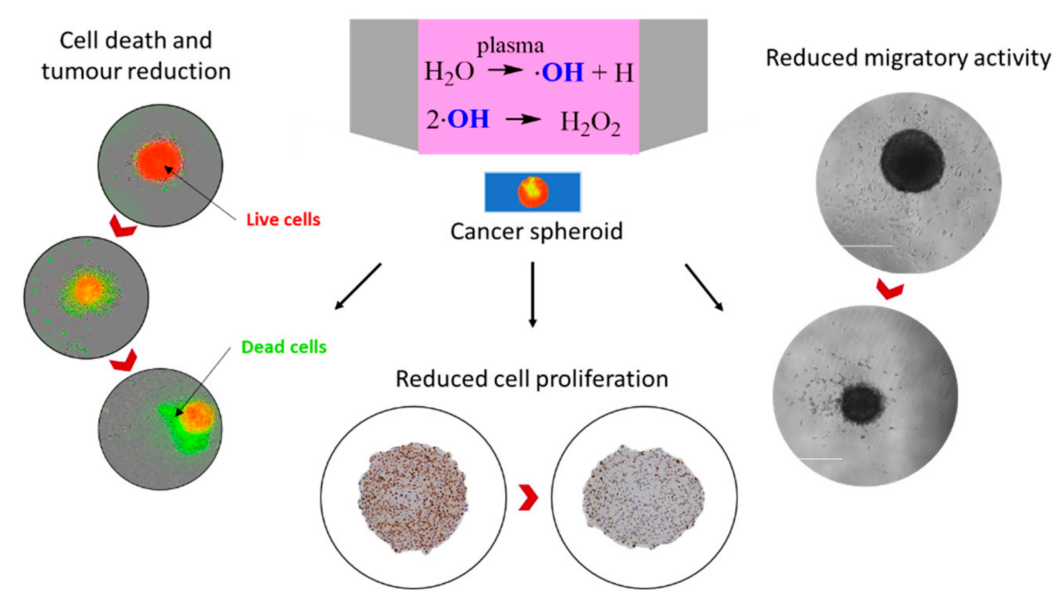

Figure 2. Strong long-term effects on glioblastoma spheroids were achieved only during direct CAP treatments due to the presence of short-lived species, such as $\bullet \mathrm{OH}$ radicals, while the plasma-generated $\mathrm{H}_{2} \mathrm{O}_{2}$ resulted only in short-term effects.

\section{Conclusions and Outlook}

Cold plasma research is a vividly growing field. Different plasma devices are developed and optimised to achieve desired effects in specific applications. Among them is the COST plasma jet: A highly tunable, computationally approachable, and easy-to-use device. In this review, we showed its applications in several studies, such as materials research (polymer etching, thin film preparation) and biomedicine (anti-bacterial and anti-cancer treatments).

The ability of the COST jet to selectively produce RONS under specific conditions is what extends its applicability beyond being a standard reference plasma jet, and makes it an extremely useful tool for CAP-related investigations. For example, $\mathrm{O} /{ }^{1} \mathrm{O}_{2} / \mathrm{O}_{3}$ can be produced when $\mathrm{O}_{2}$ is used as the feed gas admixture, and even then, the ratio between e.g., $\mathrm{O}$ and $\mathrm{O}_{3}$ is easily tailored by further altering plasma exposure conditions; $\mathrm{H}_{2} \mathrm{O}$ admixtures produce nearly exclusively $\mathrm{H}_{2} \mathrm{O}_{2}, \bullet \mathrm{OH}$ and $\bullet \mathrm{OOH}$, etc.

This brings us to the main fundamental difference between a cross-field plasma jet, such as the COST jet, and other types of CAP, such as dielectric barrier discharges (DBDs) or parallel-field APPJs. In the COST jet, the charged species, including high energy electrons, are contained within the plasma discharge region between the electrodes. The plasma electrons are responsible for most of the reactive non-equilibrium chemistry, which yields RONS upon interaction with the ambient air in the plasma jet effluent. Therefore, the effect of ambient conditions is dramatically reduced when using the COST jet compared to e.g., a DBD plasma or a parallel-field plasma jet. This also means that the COST jet is capable of producing RONS rather selectively, as opposed to e.g., the active effluent of parallel-field APPJs, where different RONS are produced from $\mathrm{N}_{2}, \mathrm{O}_{2}$ and $\mathrm{H}_{2} \mathrm{O}$ at the same time, making the total number of different RONS high. In other words, the tunable and controllable RONS-producing chemistry occurring inside the COST jet can be used to study the effects of specific reactive species in chemical and biological systems, as we show in this review. Furthermore, the absence of active effluent enables the COST jet use in studies which aim to avoid damaging the target (e.g., plasma etching/ashing, biomedical work). Some of the most important studies are summarised in Figure 3. 


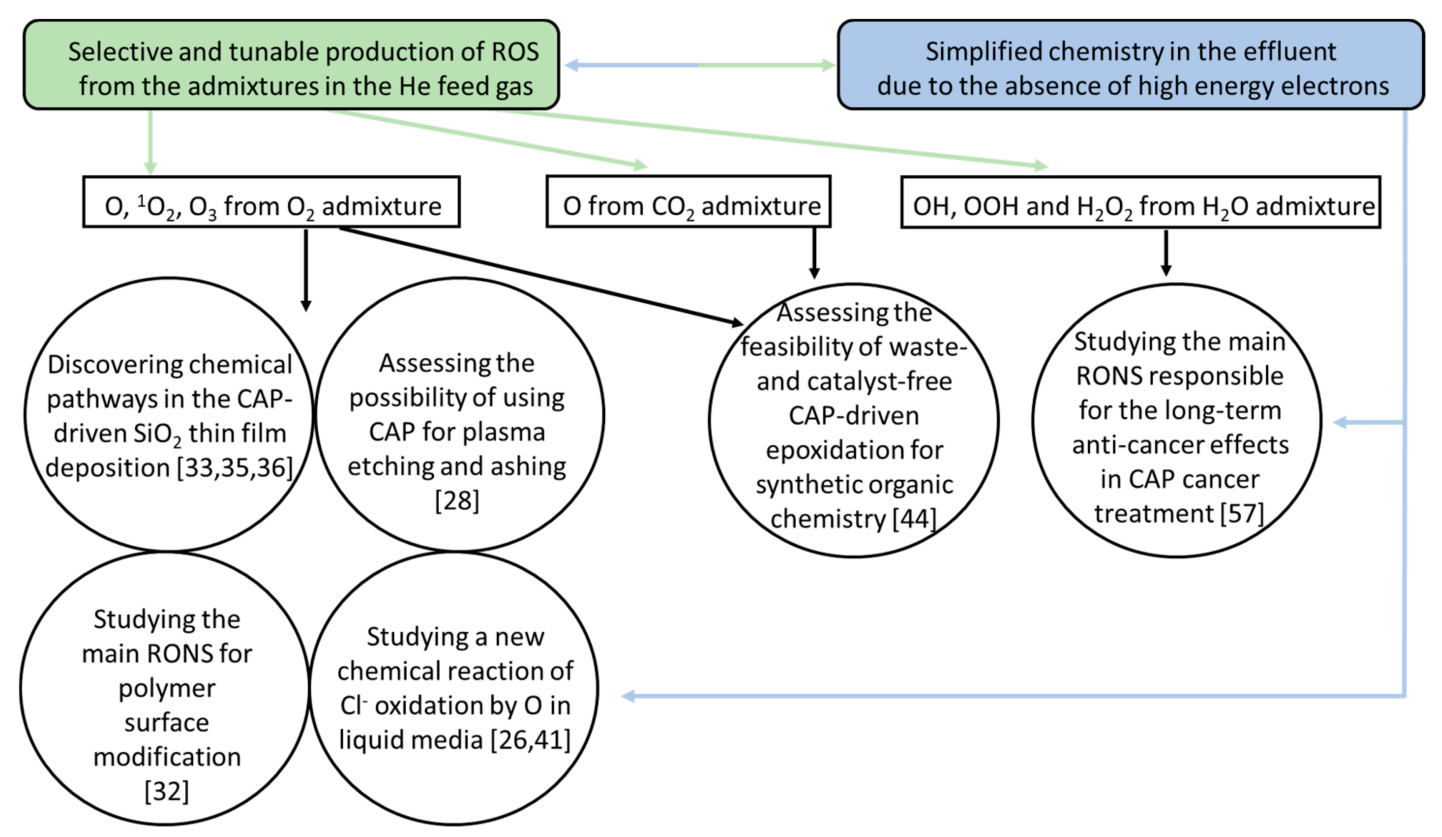

Figure 3. Some of the applied and fundamental research works with the COST plasma jet.

Several of the example works discussed here show the feasibility of using a CAP device, and specifically the COST jet, for industrial applications, e.g., in plasma etching, thin film deposition, and epoxidation in synthetic chemistry. However, it must be acknowledged that the direct use of the COST jet in an industrial or a clinical setting is limited due to several factors. For example, the COST jet requires the use of $\mathrm{He}$ as a (costly) feed gas. Nonetheless, we stress that it is indispensable in performing studies which help reveal fundamental properties of the plasma chemistry and its effects.

Author Contributions: Conceptualisation, Y.G.; Writing-original draft preparation, Y.G., V.S.-v.d.G.; Writing-review and editing, Y.G., J.G., V.S.-v.d.G., A.B.; Supervision, V.S.-v.d.G., A.B.

Funding: J.G. and V.S.-v.d.G. gratefully acknowledge funding by the DFG within PAK 816 "Plasma-cell interactions in Dermatology" and CRC 1316 "Transient Atmospheric Plasmas: from plasmas to liquids to solids".

Acknowledgments: We would like to thank Deborah O'Connell (York Plasma Institute, Department of Physics, University of York, United Kingdom) and Angela Privat-Maldonado (PLASMANT, University of Antwerp) for useful discussions.

Conflicts of Interest: The authors declare no conflict of interest.

\section{References}

1. Adamovich, I.; Baalrud, S.D.; Bogaerts, A.; Bruggeman, P.J.; Cappelli, M.; Colombo, V.; Czarnetzki, U.; Ebert, U.; Eden, J.G.; Favia, P.; et al. The 2017 Plasma Roadmap: Low temperature plasma science and technology. J. Phys. D Appl. Phys. 2017, 50, 323001. [CrossRef]

2. Nikiforov, A.; Chen, Z. (Eds.) Atmospheric Pressure Plasma-From Diagnostics to Applications; InTechOpen: London, UK, 2019.

3. Bruggeman, P.J.; Kushner, M.J.; Locke, B.R.; Gardeniers, J.G.E.; Graham, W.G.; Graves, D.B.; Hofman-Caris, R.C.H.M.; Maric, D.; Reid, J.P.; Ceriani, E.; et al. Plasma-liquid interactions: A review and roadmap. Plasma Sources Sci. Technol. 2016, 25, 053002. [CrossRef]

4. Wardenier, N.; Gorbanev, Y.; Van Moer, I.; Nikiforov, A.; Van Hulle, S.; Surmont, P.; Lynen, F.; Leys, C.; Bogaerts, A.; Vanraes, P. Removal of alachlor in water by non-thermal plasma: Reactive species and pathways in batch and continuous process. Water Res. 2019. [CrossRef] [PubMed]

5. Bogaerts, A.; Neyts, E.C. Plasma Technology: An Emerging Technology for Energy Storage. ACS Energy Lett. 2018, 3, 1013-1027. [CrossRef] 
6. Laroussi, M.; Akan, T. Arc-Free Atmospheric Pressure Cold Plasma Jets: A Review. Plasma Process. Polym. 2007, 4, 777-788. [CrossRef]

7. Winter, J.; Brandenburg, R.; Weltmann, K.-D. Atmospheric pressure plasma jets: An overview of devices and new directions. Plasma Sources Sci. Technol. 2015, 24, 064001. [CrossRef]

8. Lu, X.; Naidis, G.V.; Laroussi, M.; Reuter, S.; Graves, D.B.; Ostrikov, K. Reactive species in non-equilibrium atmospheric-pressure plasmas: Generation, transport, and biological effects. Phys. Rep. 2016, 630, 1-84. [CrossRef]

9. Laroussi, M. Plasma Medicine: A Brief Introduction. Plasma 2018, 1, 47-60. [CrossRef]

10. Gorbanev, Y.; O'Connell, D.; Chechik, V. Non-Thermal Plasma in Contact with Water: The Origin of Species. Chem. Eur. J. 2016, 22, 3496-3505. [CrossRef]

11. Reuter, S.; von Woedtke, T.; Weltmann, K.-D. The kINPen-A review on physics and chemistry of the atmospheric pressure plasma jet and its applications. J. Phys. D Appl. Phys. 2018, 51, 233001. [CrossRef]

12. Attri, P.; Kumar, N.; Park, J.H.; Yadav, D.K.; Choi, S.; Uhm, H.S.; Kim, I.T.; Choi, F.H.; Lee, W. Influence of reactive species on the modification of biomolecules generated from the soft plasma. Sci. Rep. 2015, 5, 8221. [CrossRef] [PubMed]

13. Gorbanev, Y.; Privat-Maldonado, A.; Bogaerts, A. Analysis of short-lived reactive species in plasma-air-water systems: The dos and the do nots. Anal. Chem. 2018, 90, 13151-13158. [CrossRef] [PubMed]

14. Walsh, J.L.; Kong, M.G. Contrasting characteristics of linear-field and cross-field atmospheric plasma jets. Appl. Phys. Lett. 2008, 93, 111501. [CrossRef]

15. MP1101-Biomedical Applications of Atmospheric Pressure Plasma Technology, European Cooperation in Science and Technology (COST). Available online: https://www.cost.eu/actions/MP1101 (accessed on 30 June 2019).

16. Knake, N.; Schulz-von der Gathen, V. Investigations of the spatio-temporal build-up of atomic oxygen inside the micro-scaled atmospheric pressure plasma jet. Eur. Phys. J. D 2010, 60, 645-652. [CrossRef]

17. Hemke, T.; Wollny, A.; Gebhardt, M.; Brinkmann, R.P.; Mussenbrock, T. Spatially resolved simulation of a radio-frequency driven micro-atmospheric pressure plasma jet and its effluent. J. Phys. D Appl. Phys. 2010, 44, 285206. [CrossRef]

18. Golda, J.; Held, J.; Redeker, B.; Konkowski, M.; Beijer, P.; Sobota, A.; Kroesen, G.; Braithwaite, N.S.J.; Reuter, S.; Turner, M.M.; et al. Concepts and characteristics of the 'COST Reference Microplasma Jet'. J. Phys. D Appl. Phys. 2016, 49, 08400. [CrossRef]

19. Schneider, S.; Jarzina, F.; Lackmann, J.-W.; Golda, J.; Layes, V.; Schulz-von der Gathen, V.; Bandow, J.E.; Benedikt, J. Summarizing results on the performance of a selective set of atmospheric plasma jets for separation of photons and reactive particles. J. Phys. D Appl. Phys. 2015, 48, 444001. [CrossRef]

20. Murakami, T.; Niemi, K.; Gans, T.; O'Connell, D.; Graham, W.G. Interacting kinetics of neutral and ionic species in an atmospheric-pressure helium-oxygen plasma with humid air impurities. Plasma Sources Sci. Technol. 2013, 22, 045010. [CrossRef]

21. Murakami, T.; Niemi, K.; Gans, T.; O'Connell, D.; Graham, W.G. Afterglow chemistry of atmospheric-pressure helium-oxygen plasmas with humid air impurity. Plasma Sources Sci. Technol. 2014, 23, 025005. [CrossRef]

22. Schröter, S.; Wijaikhum, A.; Gibson, A.R.; West, A.; Davies, H.L.; Minesi, N.; Dedrick, J.; Wagenaars, E.; de Oliveira, N.; Nahon, L.; et al. Chemical kinetics in an atmospheric pressure helium plasma containing humidity. Phys. Chem. Chem. Phys. 2018, 20, 24263-24286. [CrossRef]

23. Dedrick, J.; Schröter, S.; Niemi, K.; Wijaikhum, A.; Wagenaars, E.; de Oliveira, N.; Nahon, L.; Booth, J.-P.; O'Connell, D.; Gans, T. Controlled production of atomic oxygen and nitrogen in a pulsed radio-frequency atmospheric-pressure plasma. J. Phys. D Appl. Phys. 2017, 50, 455204. [CrossRef]

24. Ellerweg, D.; von Keudell, A.; Benedikt, J. Unexpected $\mathrm{O}$ and $\mathrm{O}_{3}$ production in the effluent of $\mathrm{He} / \mathrm{O}_{2}$ microplasma jets emanating into ambient air. Plasma Sources Sci. Technol. 2012, 21, 034019. [CrossRef]

25. Gorbanev, Y.; Van der Paal, J.; Van Boxem, W.; Dewilde, S.; Bogaerts, A. Reaction of chloride anion with atomic oxygen in aqueous solutions: Can cold plasma help in chemistry research? Phys. Chem. Chem. Phys. 2019, 21, 4117-4121. [CrossRef] [PubMed]

26. Oehrlein, G.S.; Phaneuf, R.J.; Graves, D.B. Plasma-polymer interactions: A review of progress in understanding polymer resist mask durability during plasma etching for nanoscale fabrication. J. Vac. Sci. Technol. B 2011, 29, 010801. [CrossRef] 
27. West, A.; van der Schans, M.; Xu, C.; Cooke, M.; Wagenaars, E. Fast, downstream removal of photoresist using reactive oxygen species from the effluent of an atmospheric pressure plasma jet. Plasma Sources Sci. Technol. 2016, 25, 02LT01. [CrossRef]

28. Hefny, M.M.; Nečas, D.; Zajíčková, L.; Benedikt, J. The transport and surface reactivity of $\mathrm{O}$ atoms during the atmospheric plasma etching of hydrogenated amorphous carbon films. Plasma Sources Sci. Technol. 2019, 28, 035010. [CrossRef]

29. Rezaei, F.; Gorbanev, Y.; Chys, M.; Nikiforov, A.; Van Hulle, S.W.H.; Cos, P.; Bogaerts, A.; De Geyter, N. Investigation of plasma-induced chemistry in organic solutions for enhanced electrospun PLA nanofibers. Plasma Process. Polym. 2018, 15, 1700226. [CrossRef]

30. Iqbal, M.; Dinh, D.K.; Abbas, Q.; Imran, M.; Sattar, H.; Ahmad, A.U. Controlled Surface Wettability by Plasma Polymer Surface Modification. Surfaces 2019, 2, 349-371. [CrossRef]

31. Shaw, D.; West, A.; Bredin, J.; Wagenaars, E. Mechanisms behind surface modification of polypropylene film using an atmospheric-pressure plasma jet. Plasma Sources Sci. Technol. 2016, 25, 065018. [CrossRef]

32. Reuter, R.; Ellerweg, D.; von Keudell, A.; Benedikt, J. Surface reactions as carbon removal mechanism in deposition of silicon dioxide films at atmospheric pressure. Appl. Phys. Lett. 2011, 98, 111502. [CrossRef]

33. Kasuya, M.; Yasui, S.; Noda, M. Deposition of $\mathrm{SiO}_{2}$ Thin Films on Polycarbonate by Atmospheric-Pressure Plasma. Jpn. J. Appl. Phys. 2012, 51, 01AC01. [CrossRef]

34. Reuter, R.; Rügner, K.; Ellerweg, D.; de los Arcos, T.; von Keudell, A.; Benedikt, J. The Role of Oxygen and Surface Reactions in the Deposition of Silicon Oxide Like Films from HMDSO at Atmospheric Pressure. Plasma Process. Polym. 2012, 9, 1116-1124. [CrossRef]

35. Rügner, K.; Reuter, R.; Ellerweg, D.; de los Arcos, T.; von Keudell, A.; Benedikt, J. Insight into the Reaction Scheme of $\mathrm{SiO}_{2}$ Film Deposition at Atmospheric Pressure. Plasma Process. Polym. 2013, 10, 1061-1073. [CrossRef]

36. Hefny, M.M.; Pattyn, C.; Lukes, P.; Benedikt, J. Atmospheric plasma generates oxygen atoms as oxidizing species in aqueous solutions. J. Phys. D Appl. Phys. 2016, 49, 404002. [CrossRef]

37. Benedikt, J.; Hefny, M.M.; Shaw, A.; Buckley, B.R.; Iza, F.; Schäkermann, S.; Bandow, J.E. The fate of plasma-generated oxygen atoms in aqueous solutions: Non-equilibrium atmospheric pressure plasmas as an efficient source of atomic $\mathrm{O}_{(\mathrm{aq})}$. Phys. Chem. Chem. Phys. 2018, 20, 12037-12042. [CrossRef] [PubMed]

38. Lin, A.; Gorbanev, Y.; De Backer, J.; Van Loenhout, J.; Van Boxem, W.; Lemière, F.; Cos, P.; Dewilde, S.; Smits, E.; Bogaerts, A. Non-Thermal Plasma as a Unique Delivery System of Short-Lived Reactive Oxygen and Nitrogen Species for Immunogenic Cell Death in Melanoma Cells. Adv. Sci. 2019, 6, 1802062. [CrossRef] [PubMed]

39. Kondeti, V.S.S.K.; Phan, C.Q.; Wende, K.; Jablonowski, H.; Gangal, U.; Granick, J.L.; Hunter, R.C.; Bruggeman, P.J. Long-lived and short-lived reactive species produced by a cold atmospheric pressure plasma jet for the inactivation of Pseudomonas aeruginosa and Staphylococcus aureus. Free Radic. Biol. Med. 2018, 124, 275-287. [CrossRef] [PubMed]

40. Jirásek, V.; Lukeš, P. Formation of reactive chlorine species in saline solution treated by non-equilibrium atmospheric pressure $\mathrm{He} / \mathrm{O}_{2}$ plasma jet. Plasma Sources Sci. Technol. 2019, 28, 035015. [CrossRef]

41. Guo, Z.; Zhou, C.; Hu, S.; Chen, Y.; Jia, X.; Lau, R.; Yang, Y. Epoxidation of trans-stilbene and cis-cyclooctene over mesoporous vanadium catalysts: Support composition and pore structure effect. Appl. Catal. A Gen. 2012, 419, 194-202. [CrossRef]

42. Gorbanev, Y.; Leifert, D.; Studer, A.; O'Connell, D.; Chechik, V. Initiating radical reactions with non-thermal plasmas. Chem. Commun. 2017, 53, 3685-3688. [CrossRef]

43. Iza, F. Plasma-Driven Organic Synthesis: Waste-Free Epoxidation. In Proceedings of the 24th International Symposium on Plasma Chemistry, Naples, Italy, 9-14 July 2019.

44. Privat-Maldonado, A.; Gorbanev, Y.; O'Connell, D.; Vann, R.; Chechik, V.; van der Woude, M.W. Non-target biomolecules alter macromolecular changes induced by bactericidal low-temperature plasma. IEEE Trans. Radiat. Plasma Med. Sci. 2018, 2, 121-128. [CrossRef] [PubMed]

45. Yan, D.; Sherman, J.H.; Keidar, M. Cold atmospheric plasma, a novel promising anti-cancer treatment modality. Oncotarget 2017, 8, 15977-15995. [CrossRef] [PubMed]

46. Graves, D.B. Mechanisms of Plasma Medicine: Coupling Plasma Physics, Biochemistry, and Biology. IEEE Trans. Radiat. Plasma Med. Sci. 2017, 1, 281-292. [CrossRef] 
47. Gorbanev, Y.; Soriano, R.; O'Connell, D.; Chechik, V. An atmospheric pressure plasma setup to investigate the reactive species formation. J. Vis. Exp. 2016, 117, e54765. [CrossRef] [PubMed]

48. Gorbanev, Y.; Verlackt, C.C.W.; Tinck, S.; Tuenter, E.; Foubert, K.; Cos, P.; Bogaerts, A. Combining experimental and modelling approaches to study the sources of reactive species induced in water by the COST RF plasma jet. Phys. Chem. Chem. Phys. 2018, 20, 2797-2808. [CrossRef]

49. Lackmann, J.-W.; Schneider, S.; Edengeiser, E.; Jarzina, F.; Brinckmann, S.; Steinborn, E.; Havenith, M.; Benedikt, J.; Bandow, J.E. Photons and particles emitted from cold atmospheric-pressure plasma inactivate bacteria and biomolecules independently and synergistically. J. R. Soc. Interface 2013, 10, 20130591. [CrossRef]

50. Lackmann, J.-W.; Wende, K.; Verlackt, C.; Golda, J.; Volzke, J.; Kogelheide, F.; Held, J.; Bekeschus, S.; Bogaerts, A.; Schulz-von der Gathen, V.; et al. Chemical fingerprints of cold physical plasmas-An experimental and computational study using cysteine as tracer compound. Sci. Rep. 2018, 8, 7736. [CrossRef]

51. Vermeylen, S.; De Waele, J.; Vanuytsel, S.; De Backer, J.; Van der Paal, J.; Ramakers, M.; Leyssens, K.; Marcq, E.; Van Audenaerde, J.; Smits, E.L.J.; et al. Cold atmospheric plasma treatment of melanoma and glioblastoma cancer cells. Plasma Process. Polym. 2016, 13, 1195-1205. [CrossRef]

52. Van der Paal, J.; Neyts, E.C.; Verlackt, C.C.W.; Bogaerts, A. Effect of lipid peroxidation on membrane permeability of cancer and normal cells subjected to oxidative stress. Chem. Sci. 2016, 7, 489-498. [CrossRef]

53. Bekeschus, S.; Wende, K.; Hefny, M.M.; Rödder, K.; Jablonowski, H.; Schmidt, A.; von Woedtke, T.; Weltmann, K.-D.; Benedikt, J. Oxygen atoms are critical in rendering THP-1 leukaemia cells susceptible to cold physical plasma-induced apoptosis. Sci. Rep. 2016, 7, 2791. [CrossRef]

54. Keidar, M. A prospectus on innovations in the plasma treatment of cancer. Phys. Plasmas 2018, $25,083504$. [CrossRef]

55. Heirman, P.; Van Boxem, W.; Bogaerts, A. Reactivity and stability of plasma-generated oxygen and nitrogen species in buffered water solution: A computational study. Phys. Chem. Chem. Phys. 2019, 21, 12881-12894. [CrossRef] [PubMed]

56. Privat-Maldonado, A.; Gorbanev, Y.; Dewilde, S.; Smits, E.; Bogaerts, A. Reduction of human glioblastoma spheroids using cold atmospheric plasma: The combined effect of short- and long-lived reactive species. Cancers 2018, 10, 394. [CrossRef] [PubMed]

(C) 2019 by the authors. Licensee MDPI, Basel, Switzerland. This article is an open access article distributed under the terms and conditions of the Creative Commons Attribution (CC BY) license (http://creativecommons.org/licenses/by/4.0/). 